\title{
A CULTURA DA MEMÓRIA E SUAS INTERFACES COM A COMUNICAÇÃO E O CONSUMO: UM ESTUDO SOBRE A MARCA GRANADO
}

\author{
La cultura de la memoria y su interacción con la comunicación y el consumo: un \\ estudio sobre la marca Granado
}

\section{Memory culture and its interfaces with communication and consumption: a study about Granado}

Mayara Luma Assmar Correia Maia Lobato ${ }^{1}$

\section{Resumo}

Neste artigo, pretende-se fazer uma análise da presença da cultura da memória nas sociedades capitalistas do século XXI, por meio de sua ressonância no universo do consumo da perfumaria Granado. Por meio das reflexões de Huyssen, Nora, Nunes, Kopytoff e outros, estuda-se a priorização do estilo retrô na ambientação das lojas, nos rótulos e embalagens e nas fórmulas dos produtos da marca brasileira, constatando a valorização da memória e seus componentes simbólico-afetivos para a venda de produtos. Palavras-chave: cultura da memória, consumo, Granado, simbolismo, afetividade.

\begin{abstract}
In this article, we intend to make an analysis of the presence of memory culture in capitalist societies of the 21 st century, through its resonance in the consumption universe of Granado perfumery. Through reflections made by Huyssen, Nora, Nunes, Kopytoff and others, we study the prioritization of retro style in the ambiance of the stores, in labels, packaging and in formulas of products of the Brazilian brand, noting the reinforcement of memory and its symbolic-affective components, aiming the sale of products.
\end{abstract}

Keywords: memory culture, consumption, Granado, symbolism, affectivity.

\footnotetext{
${ }^{1}$ Doutoranda do Programa de Pós-Graduação em Comunicação e Práticas de Consumo da ESPM/SP. Mestre em Comunicação pela Faculdade Cásper Líbero (2012). Jornalista graduada pela Universidade da Amazônia. Professora do Centro Universitário FIAM-FAAM. Mediadora do Núcleo de Estudos de Gênero e Sexualidade (NUGE - FIAM-FAAM) e membro do Grupo de Pesquisa em Subjetividade, Comunicação e Consumo (GRUSCCO - ESPM/SP). Telefone: (11) 98660-0096. E-mail: mayaraluma@gmail.com.
} 
A cultura da memória e suas interfaces com a comunicação e o consumo: um estudo sobre a marca Granado

de Mayara Luma Assmar Correia Maia Lobato

\section{Resumen}

En este artículo, analizamos la presencia de la cultura de la memoria en las sociedades capitalistas del siglo XXI, a través de su resonancia en el universo del consumo de la perfumería Granado. A través de reflexiones de Huyssen, Nora, Nunes, Kopytoff y otros, se estudia la priorización del estilo retro en el ambiente de las tiendas, en etiquetas y embalajes y en fórmulas de productos de la marca brasileña, identificando la fortificación de la memoria y sus componentes simbólico-afectivos para la venta de productos.

Palabras-clave: cultura de la memoria, consumo, Granado, simbolismo, afectividad.

\section{INTRODUÇÃO}

Ao longo do século $\mathrm{XX}$, as expectativas para o futuro alimentaram muitos devaneios. Como seria o porvir? O famigerado século XXI? Não foi à toa que filmes como "2001 - Uma Odisseia no Espaço" ou mesmo "De Volta para o Futuro" alcançaram sucesso estrondoso nas telas do cinema, permanecendo ainda hoje em muitas construções imaginárias, embora o futuro que chegou não seja exatamente como aquele sonhado pela ficção. Se as fantasias futuristas fizeram sucesso algum tempo atrás, nos dias atuais, parecemos nos voltar muito mais ao passado, em que reside uma certa nostalgia e um desejo de retorno.

Huyssen (2000), no alvorecer do novo século, captou bem o fascínio que o passado começava a provocar e traduziu-o no livro "Seduzidos pela Memória" - o título não poderia ser melhor. Dezesseis anos depois dessa publicação, observamos que estamos, de fato, seduzidos pelo que o passado pode nos trazer, o que se reflete na moda vintage, na decoração que prioriza elementos antigos, nos antiquários que se multiplicam, nas tentativas - bastante válidas - de preservação da arquitetura antiga, no número de museus que vemos crescer a cada dia. De diferentes maneiras, as sociedades capitalistas se valem dessa atração pelo passado. Exemplos claros disso são as coleções "retrô" que muitas lojas, de vários segmentos, vêm lançando, como a da Coca-Cola, vendida pela Tok\&Stok, com inspiração nos anos 1950. 
A cultura da memória e suas interfaces com a comunicação e o consumo: um estudo sobre a marca Granado

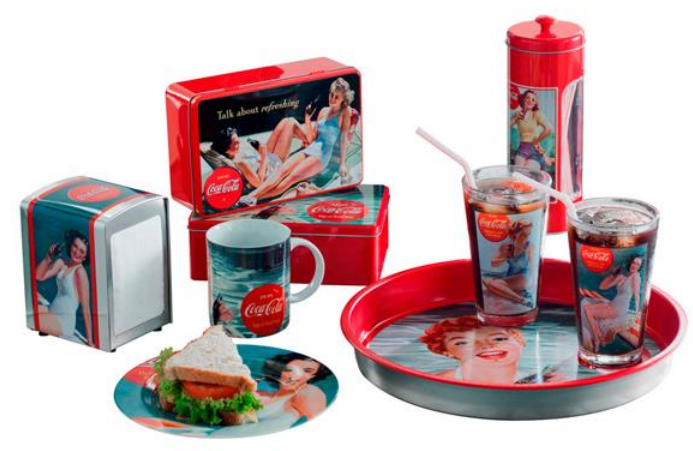

Imagem 1: Coleção retrô da Coca-Cola (acervo Tok\&Stok).

Dentro desse cenário, uma loja nos chamou a atenção, a Granado, casa de produtos de beleza e assepsia corporal fundada em 1870, no Rio de Janeiro. Com o crescimento dos negócios ao longo de mais de um século, a perfumaria se tornou internacionalmente conhecida e possui lojas distribuídas em diversos estados do país. Uma de suas grandes marcas é o aspecto retrô que cultiva na arquitetura e decoração das lojas, nos produtos e em suas embalagens. As lojas remetem ao início do século passado, enquanto que as embalagens podem ser inspiradas em diferentes períodos, muitas vezes resgatando o design original dos rótulos. Para construir este estudo, vamos tomar como base as ideias trabalhadas por autores como Huyssen (2000), Kopytoff (2014), Pollak (1989), Nora (1993), Rocha e Aucar (2014) e Nunes (2015).

\section{RUMO AOS PASSADOS PRESENTES}

O que guardamos do passado? O que fazemos com ele? Do que lembramos? Quando afirmamos que o passado, hoje, passou a exercer um certo fascínio, essas são algumas das perguntas que vêm à tona, ou seja, o que comumente nos perguntamos é: que passado é este de que nós lembramos? É verdade que construímos a memória a partir do que foi vivido, processo que envolve alto grau de subjetividade; mas, quando se trata de um tempo distante, dependemos exclusivamente daquilo que nos contam. E muito do que sabemos foi-nos contado em museus. Por isso, em uma cultura em que há a valorização da memória, naturalmente, haverá também a valorização de museus. Harvey (1989) traz dados interessantes sobre o boom de museus pelo mundo, tanto em sociedades ocidentais 
A cultura da memória e suas interfaces com a comunicação e o consumo: um estudo sobre a marca Granado

de Mayara Luma Assmar Correia Maia Lobato

quanto orientais, no fim do século passado. Na Inglaterra, entre os anos 1980 e 1990, abria-se um museu a cada três semanas; no Japão, foram 500 abertos entre 1975 e 1990.

Huyssen (2000:9), em sintonia com o pensamento do autor supracitado, afirma que "a partir da década de 1980 o foco parece ter-se deslocado dos futuros presentes para os passados presentes". O estudioso acredita que existem, hoje, "obsessões com a memória e com o passado" (Huyssen 2000:15) e continua: "não há dúvida de que o mundo está sendo musealizado e que todos nós representamos os nossos papéis neste processo" (Huyssen 2000:15). Diante disso, o autor acredita que vivemos em uma cultura da memória, que começou sua disseminação nas sociedades do Atlântico-Norte, mas se expandiu para muitos outros lugares. No final dos anos 1980, esse debate chegou à América Latina, inclusive ao Brasil, com o fim das ditaduras e a ascensão de todas as memórias que foram abafadas ao longo daquele período.

O mesmo debate se mostrou relevante nos países pós-comunistas do leste europeu e da antiga União Soviética, provando que se faz diferentes usos políticos da memória: “a disseminação geográfica da cultura da memória é tão ampla quanto é variado o uso político da memória” (Huyssen 2000:16). Muito do que se vê nos museus, por exemplo, é reflexo dos embates políticos em torno do que se quer contar sobre a história para as gerações futuras. Nesses espaços, assim como em monumentos históricos ou nos livros de história, por exemplo, "a memória entra em disputa", como coloca Pollak (1989:4), pois passa a existir "conflito e competição entre memórias concorrentes" para formação de uma memória coletiva de tipo nacional:

O trabalho de enquadramento da memória se alimenta do material fornecida pela história. Esse material pode sem dúvida ser interpretado e combinado a um sem-número de referências associadas; guiado pela preocupação não apenas de manter as fronteiras sociais, mas também de modificá-las, esse trabalho reinterpreta incessantemente o passado em função dos combates do presente e do futuro. (Pollak 1989:9-10).

Em suma, o que se encontra nos exemplos aqui colocados é a memória oficial de uma nação, que, conforme propõe Pollak (1989), é sempre construída e, às vezes, pode ser forjada, o que quase sempre é bastante negativo, podendo gerar “memórias 'proibidas' e, portanto, "clandestinas"” e, ainda, conduzir "as vítimas da história ao silêncio e à renegação de si mesmas" (Pollak 1989:5-7). No entanto, é importante salientar, a característica de construção que marca a memória, seja ela oficial, coletiva ou individual, não necessariamente significa um problema. Nas palavras de Huyssen (2000:16): 
A cultura da memória e suas interfaces com a comunicação e o consumo: um estudo sobre a marca Granado

de Mayara Luma Assmar Correia Maia Lobato

[...] nem sempre é fácil traçar uma linha de separação entre passado mítico e passado real, um dos nós de qualquer política de memória em qualquer lugar. O real pode ser mitologizado tanto quanto o mítico pode engendrar fortes efeitos de realidade. Em suma, a memória se tornou uma obsessão cultural de proporções monumentais em todos os pontos do planeta.

Pelas ideias dos autores apresentados até aqui, história e memória parecem bastante interligadas - e estão verdadeiramente. Mas Nora (1993:9) aponta para importantes diferenças entre as duas: "memória, história: longe de serem sinônimos, tomamos consciência que tudo opõe uma à outra". O autor entra nesse debate tratando de memória coletiva nacional, tema também presente em Pollak e Huyssen, conforme apresentado nos parágrafos anteriores. Para Nora (1993:10), "todos os grandes remanejamentos históricos consistiram em alargar o campo da memória coletiva". Usando seu próprio país, a França, como exemplo, o autor enfatiza que "história, memória, Nação mantiveram, então, mais do que uma circulação natural: uma circularidade complementar, uma simbiose em todos os níveis” (Nora 1993:11). No entanto, no trabalho do autor, há muita crítica em relação exatamente a essa tríade:

\begin{abstract}
Museu, arquivo, cemitério e coleções, festas, aniversários, tratados, processos verbais, monumentos, santuários, associações, são os marcos testemunhas de uma outra era, das ilusões de eternidade. Daí o aspecto nostálgico desses empreendimentos de piedade, patéticos e glaciais. São os rituais de uma sociedade sem ritual; sacralizações passageiras numa sociedade que dessacraliza; fidelidades particulares de uma sociedade que aplaina os particularismos; diferenciações efetivas numa sociedade que nivela por princípio; sinais de reconhecimento e pertencimento de grupo numa sociedade que só tende a reconhecer indivíduos iguais e idênticos. (Nora 1993:13).
\end{abstract}

Entre suas críticas está a noção de que "toda a história entrou em sua idade historiográfica, consumindo sua desidentificação com a memória” (Nora 1993:11). Nesse sentido, o autor demarca uma oposição entre história e memória: "a história é a reconstrução sempre problemática e incompleta do que não existe mais. A memória é um fenômeno sempre atual, um elo vivido no eterno presente" (Nora 1993:9). Nora opõe memória e história no sentido de que a primeira é algo pessoal, que envolve aspectos subjetivos; a segunda parece algo que nos é transmitido de forma unilateral, como uma memória coletiva construída. Por isso, ele afirma que "a história tornou-se uma ciência social; e a memória um fenômeno puramente privado" (Nora 1993:12).

Entre as distinções que Nora faz entre memória e história, para nós, o que parece mais interessante está exatamente no sentido de mostrar a primeira como algo vivo, que envolve subjetividade e afeto. Aí pode estar uma explicação do motivo de a memória, 
A cultura da memória e suas interfaces com a comunicação e o consumo: um estudo sobre a marca Granado

de Mayara Luma Assmar Correia Maia Lobato

hoje, ter ganhado tanta importância, em especial nas sociedades capitalistas, nas quais vem sendo mercantilizada. Se, conforme defende o mesmo autor, "não há memória espontânea”, pois suas “operações não são naturais” (Nora 1993:13); seriam o mercado e os artifícios de que se vale, como a publicidade, por exemplo, espécies de estimulantes de nossa memória? Valer-se-ia a sociedade capitalista do componente simbólico-afetivo que envolve os nossos processos de construção da memória para estimular o consumo e garantir sua perpetuação?

\section{MEMÓRIA E CONSUMO EM DIÁLOGO}

Retornando ao pensamento de Huyssen (2000:15), o autor acredita que a indústria cultural do ocidente tem promovido uma "comercialização crescentemente bem-sucedida da memória". Como coloca Nunes (2015:41), "as massas querem ser tocadas emocionalmente", o que fez com que o apelo à memória se tornasse um artifício das sociedades de consumo. Para a autora, "as escolhas sempre se ligam aos afetos" (Nunes 2015:60), inclusive as escolhas dos produtos/serviços que serão consumidos, daí os estímulos à memória, sempre ligada à afetividade, promovidos pelo mercado. Kopytoff (2010) também traz argumentos interessantes a este debate, afirmando que o valor dos objetos é conferido de forma sentimental e por escolha individual:

O que é peculiar às sociedades complexas é que sua mercantilização publicamente reconhecida opera lado a lado com inúmeros esquemas de valoração e singularização propostos por indivíduos, categorias sociais e grupos, e que esses esquemas apresentam um conflito insolúvel com a mercantilização pública e entram também em conflito uns com os outros. (Kopytoff 2010:108).

A memória ganha importância conforme se tornam "as regras menos claras e mais abertas às interpretações individuais e aos sistemas idiossincráticos de valores” (Kopytoff 2010:108). A prática de colecionar objetos se torna comum em nossas sociedades, num processo gradativo em que o "velho" se torna vintage ou retrô: "coisas velhas, como latas de cerveja, caixas de fósforos e revistas em quadrinho, de repente, assumem valor, e passa a ser vantajoso colecioná-las" (Kopytoff 2010:109). Nesse contexto, não necessariamente apenas elementos antigos se tornam colecionáveis ou ganham visibilidade; uma série de produtos que remetem à memória de um determinado período passam, também, a ser bastante valorizados. É o que muitas lojas vêm fazendo ao redor do mundo; no Brasil, também temos exemplos interessantes. 
A cultura da memória e suas interfaces com a comunicação e o consumo: um estudo sobre a marca Granado

de Mayara Luma Assmar Correia Maia Lobato

A grife de roupas Ellus, por exemplo, lançou recentemente uma coleção de camisas do Mickey, que apela não só ao vintage, mas a um passado vivido por muitas pessoas que assistiam ao desenho ou que, na infância, assistiram aos filmes do personagem, estimulando, dessa forma, um consumo afetivo por meio da memória. Esse tipo de produto ilustra o pensamento de que "os objetos são pensados mais pelos sentidos que podem ter, do que pelo compromisso com sua aplicação prática" (Rocha; Aucar 2014:155). O mesmo vale, por exemplo, para os objetos da Coca-Cola comercializados pela loja de decoração Tok\&Stok, com inspiração nos anos 1950. Ainda que os consumidores não tenham uma memória, digamos, efetivamente vivida do período, os produtos remetem a alguma questão individual, subjetiva, tornando seu consumo "simbólico-afetivo, isto é, revestido de significados imateriais e emocionais", nas palavras de Nunes (2015:29).

Os muitos exemplos semelhantes aos que acabamos de expor provam que o mundo não é tão pautado pela razão como se costuma supor. Segundo Rocha e Aucar (2014:157): "é preciso ponderar como o pensamento mágico sobrevive em meio a um mundo que estabelece a razão como eixo de funcionamento", evocando diferentes mitologias e construções imaginárias que escapam à racionalidade moderna, desafiandoa e pondo-a em xeque. Um dos setores nos quais prevalece o pensamento mágico é na atividade do consumo. Não estamos dizendo aqui que essa seja uma prática dotada somente de não racionalidade, mas, sim, que se estrutura muito mais a partir de um plano simbólico do que racional. De forma sensata, propõem Rocha e Aucar (2014:159): "o ato de consumo é a junção das necessidades simbolicamente construídas com os limites da possibilidade de compra”. Isso sinaliza, portanto, que consumir é ao mesmo tempo reagir a uma necessidade específica e ingressar em uma teia de significados e operações de sentido.

Entre os vários exemplos de consumo de memória que encontramos em nossas sociedades hoje, escolhemos a perfumaria Granado como objeto de estudo deste trabalho por ilustrar muitas das ideias aqui discutidas. A exploração do passado e, portanto, o apelo à memória, ao afetivo, ao simbólico está presente de diferentes maneiras em nosso objeto, desde a ambientação das lojas ao uniforme dos vendedores, passando pelos rótulos, pela publicidade da marca e até mesmo por componentes de alguns produtos ou pelo próprio produto em si, como o polvilho antisséptico, produto mais antigo ainda fabricado pela empresa e cuja fórmula original permanece inalterada. 
A cultura da memória e suas interfaces com a comunicação e o consumo: um estudo sobre a marca Granado

\section{GRANADO E O CONSUMO DE MEMÓRIA}

A Granado foi fundada em 1870 por um português, no centro da capital do Rio de Janeiro. Hoje perfumaria, a marca foi fundada como farmácia, produzindo artigos manipulados a partir de extratos vegetais de plantas, ervas e flores brasileiras. Não demorou para que a loja fizesse sucesso e ganhasse o título de Farmácia Oficial da Família Real Brasileira, concedido por D. Pedro II, então imperador do Brasil. Hoje, seu proprietário e presidente é o inglês Christopher Freeman, que, em 2004, incorporou à empresa a Phebo, uma fábrica de sabonetes localizada em Belém (PA). Apesar de mais de cem anos de existência, muito da marca foi preservado, como a primeira loja, localizada na antiga rua Direita, no Rio de Janeiro, ainda em funcionamento, ou mesmo a fórmula, até hoje inalterada, de seu polvilho antisséptico - indicando que a memória está presente de diferentes maneiras na empresa.

A Granado se intitula “a botica mais antiga do Brasil”, termo que chama atenção, pois foi comum no início do século XX para designar casas que preparavam e vendiam medicamentos e produtos de cuidados pessoais. A palavra caiu em desuso, mas a marca continua dela fazendo uso, com o objetivo de valorizar sua história e convertê-la em um atributo positivo. Outro elemento que também remete à longa trajetória tanto da Granado quanto da Phebo são as fontes de escrita utilizadas: os dois nomes resgataram seu design original. Acompanhando o nome da primeira vem escrito "pharmácias", como na grafia antiga; na segunda, vem o ano de sua fundação: 1932. Em ambos os casos, novamente, a tentativa é remeter ao passado.

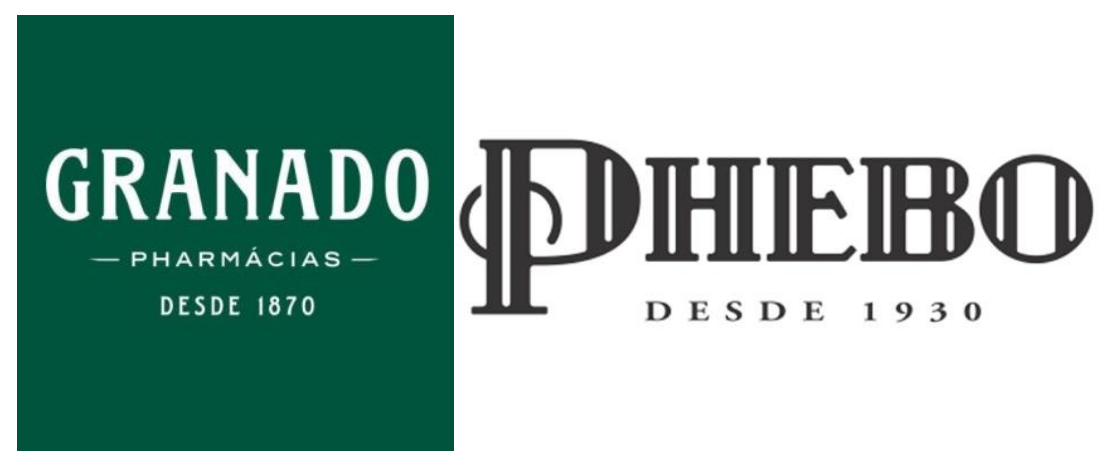

Imagens 2a e 2b: Logos da Granado e da Phebo (acervo da empresa).

O nome "Granado Pharmácias" estampa de forma tímida a fachada das lojas, que chamam muito mais atenção pelo estilo retrô. Predominam nesses espaços o vidro e o 
A cultura da memória e suas interfaces com a comunicação e o consumo: um estudo sobre a marca Granado

de Mayara Luma Assmar Correia Maia Lobato

ferro, materiais considerados os mais avançados em construção do fim do século XIX e início do XX, usados em edificações marcantes do período, como o Mercado Municipal de São Paulo (1933) e a Estação da Luz (1901), a tradicional Confeitaria Colombo $(1894)^{2}$, no Rio de Janeiro, e o Gasômetro, em Belém, construído pela Companhia de Gás do Pará, entre muitos outros exemplos. No interior, as lojas seguem o mesmo estilo: grandes vitrines em madeira e vidro dispostas por todo o ambiente e armário em madeira para guardar os produtos. Os espaços de venda são bastante semelhantes entre si e, em todos, o piso é em azulejo que imita estilo antigo. Por todos esses elementos, é possível considerar que esses ambientes são símbolos da cultura da memória de que fala Huyssen (2000), pois narrativizam o passado, tornando-o presente em nossas vidas e promovendo “a comercialização em massa da nostalgia” (Huyssen 2000:14).

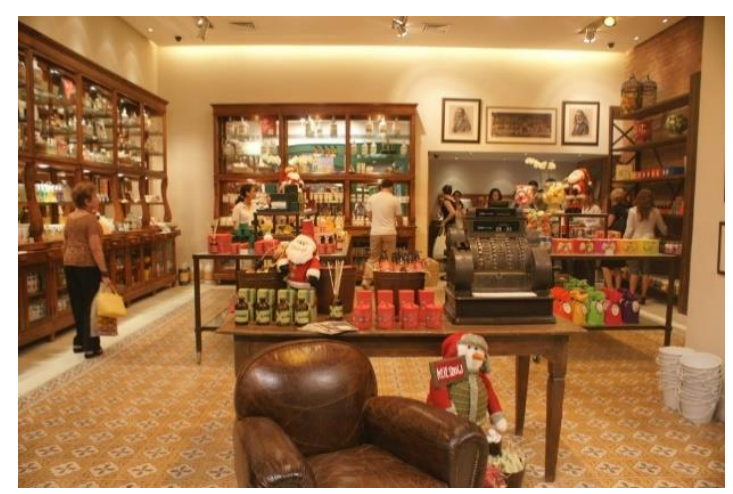

Imagem 3: Interior de uma das lojas da Granado.

Ainda como decoração das lojas, máquinas registradoras antigas entram em contraste com modernos computadores nos caixas; balanças, móveis clássicos e campanhas publicitárias remotas da marca ajudam a estimular a "memória imaginada" dos consumidores. Aplicando as ideias de Huyssen (2000) a esta análise, a loja se estruturaria dessa forma pois "o passado está vendendo mais do que o futuro" (Huyssen 2000:24), mesmo que se trate de uma "memória imaginada", pautada, portanto, em uma época impossível de ser lembrada por meio de uma "memória vivida", pelo tempo de distância que separa o passado explorado pela Granado do presente.

\footnotetext{
${ }^{2}$ Assim como a Granado, a confeitaria manteve em funcionamento sua primeira loja, no centro da capital fluminense. Nela, é possível observar o mobiliário da época e admirar um vitral que ocupa boa parte do teto. A marca investe no vintage, comercializando doces em latas que seguem no rótulo um estilo antigo.
} 
A cultura da memória e suas interfaces com a comunicação e o consumo: um estudo sobre a marca Granado

de Mayara Luma Assmar Correia Maia Lobato

Huyssen (2000:37) faz a diferenciação entre memória vivida e imaginada. Como o nome propõe, a primeira seria uma memória produzida a partir de um passado habitado; enquanto que a segunda é produzida a partir do que nos contam outras pessoas, livros, fotografias, museus, monumentos históricos etc. $\mathrm{O}$ autor insiste que isso não significa que uma seja "real" e a outra virtual, pois toda memória "é virtual por sua própria natureza" (Huyssen 2000:37).

Inspirada, portanto em uma "memória imaginada", a ambientação das lojas da Granado se sustenta, de acordo com Pollak (1989:9), em "uma permanente interação entre o vivido e o aprendido, o vivido e o transmitido". Resgatando também as ideias de Huyssen (2000:24), é possível afirmar que lojas como a analisada fazem sucesso porque "estamos obcecados com re-representação, repetição, replicação e com a cultura da cópia, com ou sem o original".

As representações do passado estão presentes também em placas de metal que a loja comercializa, único produto que se desvia da linha de negócios principal da empresa - no mesmo material, há latas, por exemplo, mas que servem de embalagem para sabonetes, perfumes etc. Essas placas, nas quais estão reproduzidos alguns reclames como era chamada a publicidade no passado - da Granado, têm fins meramente decorativos, o que nos obriga a pensar no consumo a partir de "uma interpretação menos focada em produtos e serviços, em si, mas que considera a inserção do consumo em toda uma cena ou rede midiática, rizomática e dinâmica" (Rocha apud Nunes 2015:15). O consumo e a aquisição de produtos como as placas apresentadas nos ajuda a compreender que há muito de mágico, simbólico e afetivo nessa prática: “Através da compra, a identidade do produto é transferida para a identidade do sujeito, permitindo uma realização, uma abundância efêmera, por isso é uma prática revestida de emoções, afetos, sensibilidades" (Rocha e Aucar 2014:159). 
A cultura da memória e suas interfaces com a comunicação e o consumo: um estudo sobre a marca Granado

de Mayara Luma Assmar Correia Maia Lobato

Assim como a ambientação da loja, os rótulos dos produtos também seguem o estilo retrô. Fazendo uma adaptação das ideias de Pollak (1989:10), isso mostra que "a memória é assim guardada e solidificada nas pedras" - no caso de nossa análise, nos rótulos e embalagens. Alguns produtos mantiveram suas embalagens originais, outros foram pensados de acordo com o estilo antigo da marca. Os sabonetes tradicionais da Phebo, por exemplo, mantiveram sua fórmula, à base de glicerina, quase que inalterada; o formato oval se tornou sua maior marca e a embalagem sofreu poucas alterações. A Granado, por sua vez, tem uma linha de produtos intitulada vintage, em que são resgatadas fragrâncias da década de 1930, seus rótulos e embalagens.

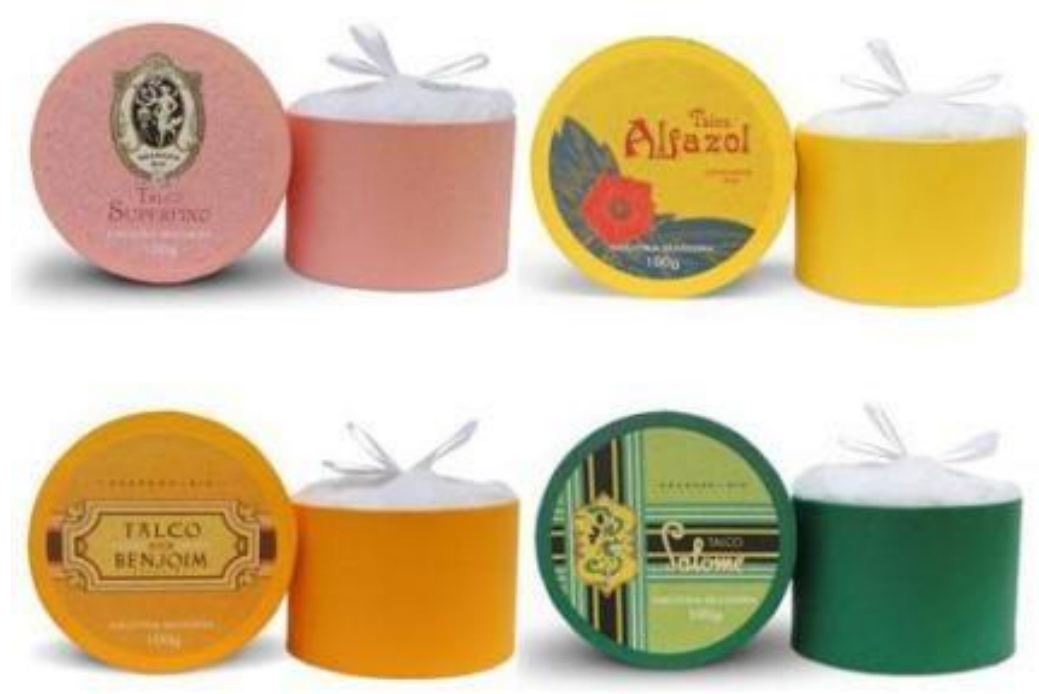

Imagem 4: talcos da linha vintage (acervo Granado).

Entre os vários elementos que chamam atenção, destaca-se a união entre o novo e o velho: a empresa trabalha com as tecnologias mais avançadas na sua produção e, ao mesmo tempo, mantém o que remonta à tradição, sustentando e reproduzindo a memória da marca, com fins comerciais, principalmente. Na linha "vintage", por exemplo, as fragrâncias originais ganharam releituras baseadas em modernas tecnologias, como a base de produção, que é $100 \%$ vegetal.

Apesar das muitas lojas próprias que possui, abertas a partir de 2004, depois da venda da marca, seus produtos são comercializados também em farmácias e supermercados. Produtos antigos, ou que pelo menos remetem a outros períodos, não são mais encontrados apenas nos espaços antes a eles destinados. Sua existência passou a 
A cultura da memória e suas interfaces com a comunicação e o consumo: um estudo sobre a marca Granado

de Mayara Luma Assmar Correia Maia Lobato

extrapolar esses ambientes, podendo ser encontrada em diversos lugares. Aspecto que se torna bastante interessante se considerarmos que isso pode fazer parte de um processo de musealização, tratado por Hermann Lübbe (Huyssen 2000:27), pelo qual as sociedades passam hoje:

Ele [Lübbe] mostrou como a musealização já não era mais ligada à instituição do museu no sentido estrito, mas tinha se infiltrado em todas as áreas da vida cotidiana. $O$ diagnóstico de Lübbe assinalou o historicismo expansivo da nossa cultura contemporânea e afirmou que nunca antes o presente tinha ficado tão obcecado com o passado como agora. (Huyssen 2000:27).

Todos os elementos concernentes à marca estudados aqui mostram seu apelo simbólico-afetivo à memória, seja ela vivida ou imaginada, dos consumidores. O rótulo, as embalagens, o nome dos produtos e suas fragrâncias tentam transportar o consumidor para o passado; para isso, estimulam sua sensorialidade. Assim, os artifícios combinados do produto podem remeter o usuário a diferentes tipos de lembranças e sentimentos, o que ajuda a demonstrar que há muito de mágico e de não racional na atividade de consumo, conforme colocam Rocha e Aucar (2014:161): "uma das maiores contradições da racionalidade capitalista é justamente a de que reside no pensamento mágico a propulsão imaginária que vai levar todos nós ao consumo".

Um dos elementos mais importantes que estimulam essa "propulsão imaginária", em grande medida responsável pelo consumo, é a publicidade. É curioso que, em nossa análise, não identificamos, na Granado, um forte apelo publicitário. A marca, por exemplo, não veicula campanhas na tevê; sua prioridade são os meios impressos, em especial as revistas femininas - o que denota a preferência da empresa por um tipo de publicidade mais segmentado. Até disso, pode-se fazer uma interpretação a partir da valorização do passado: há algo de tradicionalismo em manter os veículos impressos como os principais meios de anunciar, mesmo porque em um vídeo publicitário para televisão, por exemplo, seria mais difícil manter o estilo retrô que as publicidades da marca também seguem. 
A cultura da memória e suas interfaces com a comunicação e o consumo: um estudo sobre a marca Granado

de Mayara Luma Assmar Correia Maia Lobato

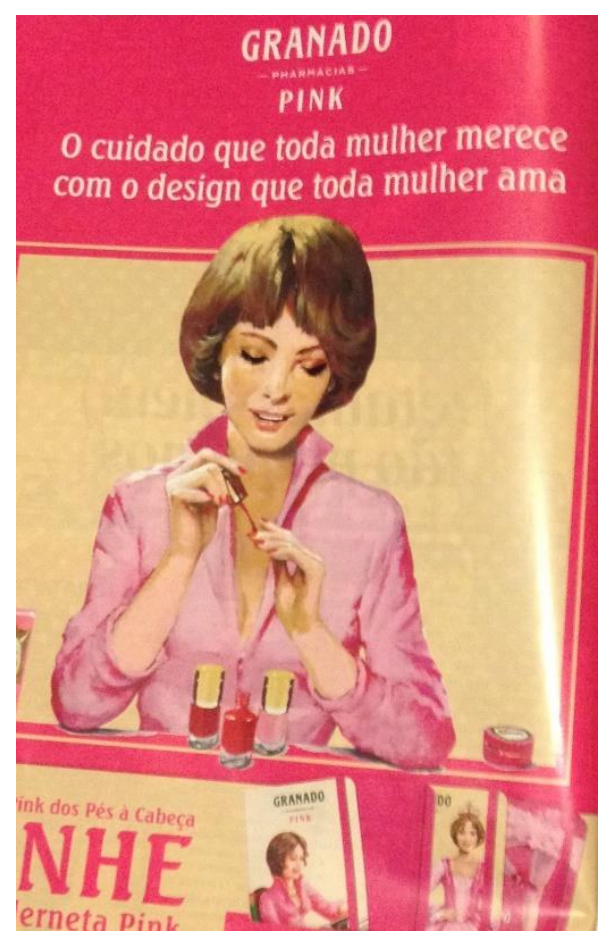

Imagem 5: exemplo de peça publicitária veiculada pela Granado em revistas (arquivo pessoal).

Independentemente do volume de publicidade que a Granado veicula, são instrumentos usados não só por ela, como pelo mercado de forma geral, para atrair o consumidor. Como afirmam Rocha e Aucar (2014:148): “dentro do eixo histórico, de cerne capitalista, a publicidade se estrutura como um pilar valioso, de transformação e produção da ordem simbólica, um mediador das relações sociais". Assim como qualquer material publicitário, o da Granado também espera cativar o possível consumidor a partir do simbólico e do afetivo; a diferença é que a empresa aqui analisada busca esses elementos a partir da memória. Há a tentativa de despertar algum tipo de lembrança, algum sentimento nostálgico, ainda que seja em relação a um tempo não vivido, ou seja, um sentimento de nostalgia a partir da memória imaginada, evidenciando que "as práticas de consumo estão carregadas de simbolismos" (Rocha e Aucar 2014:151).

Caminhando já para o fim desta análise, muitos são os motivos que podem levar a Granado à valorização do passado e da memória, o que só poderia ser decifrado com entrevistas com profissionais da empresa, o que não é objetivo deste trabalho. Ao promover releituras de fragrâncias que fizeram sucesso no passado, retomar antigos rótulos, manter fórmulas e formatos de produtos quase inalterados, o que se pode observar por trás de tudo isso é uma tentativa de demonstrar que a marca tem história e tradição, que a sua sobrevivência por um tempo tão extenso atesta a qualidade de seus produtos. 
A cultura da memória e suas interfaces com a comunicação e o consumo: um estudo sobre a marca Granado

de Mayara Luma Assmar Correia Maia Lobato

Para Granado, o passado se tornou não só comercializável, como lucrativo - mesmo sem termos acesso aos resultados financeiros da empresa, é possível observar isso pela expansão da marca nos últimos anos e pela manutenção de lojas em shoppings por todo o Brasil. Conectando nossa reflexão às ideias de Kopytoff (2010), é como se a valorização da história da marca tornasse possível a escrita da biografia dos objetos que fabrica, a qual não seria vazia; muito pelo contrário, o que se propõe é que há todo um passado por trás da marca:

Ao fazer a biografia de uma coisa, far-se-iam perguntas similares às que se fazem às pessoas: Quais são, sociologicamente, as possibilidades biográficas inerentes a esses "status", e à época e à cultura, e como se concretizam essas possibilidades? De onde vem a coisa, e quem a fabricou? Qual foi a sua carreira até aqui, e qual é a carreira que as pessoas consideram ideal para esse tipo de coisa? Quais são as 'idades' ou as fases $d a$ 'vida' reconhecidas de uma coisa, e quais são os mercados culturais para elas? Como mudam os usos da coisa conforme ela fica mais velha, e o que lhe acontece quando a sua utilidade chega ao fim? (Kopytoff 2010:92).

\section{CONSIDERAÇÕES FINAIS}

Ao longo deste artigo, foram apresentados aspectos relacionados à cultura da memória em que vivemos hoje. Se, num passado não distante, eram os devaneios sobre o futuro o que vendia, fosse vestimenta, objetos de decoração ou filmes, atualmente, o mercado se volta muito mais para o passado, alimentando um sentimento nostálgico nos consumidores, a ideia de que o ontem foi sempre melhor que o hoje. Entre os muitos exemplos de como a cultura da memória está presente nas sociedades capitalistas atuais, o da perfumaria Granado se mostrou profícuo, pois permitiu observar na prática muitas das ideias de autores que tratam do assunto, como Huyssen (2000), Kopytoff (2014), Pollak (1989), Nora (1993), Rocha e Aucar (2014) e Nunes (2015), que nos ajudaram a construir este estudo.

A empresa aqui analisada entra na extensa onda de moda vintage ou retrô que, já há algum tempo, vem ganhando força. Durante o estudo, observou-se que a cultura da memória, associada ao capitalismo, faz com que a história por trás dos objetos passe a ser valorizada, aspecto que a Granado tenta imprimir em seus produtos desde o rótulo, na expectativa de que seja possível escrever suas biografias (Kopytoff, 2010). Embora tudo na empresa siga bastante o estilo mais antigo, das lojas à fórmula dos produtos, a linha "vintage" da Granado pode render, ainda, estudos mais aprofundados no futuro; assim como a combinação do moderno com o clássico, em especial nas tecnologias utilizadas 
A cultura da memória e suas interfaces com a comunicação e o consumo: um estudo sobre a marca Granado

de Mayara Luma Assmar Correia Maia Lobato

na produção, que precisam combinar as fórmulas tradicionais com o maquinário avançado de hoje.

Aqui, concentramo-nos em estudar a marca e os artifícios de que ela se vale para alcançar a memória simbólico-afetiva do consumidor, a porção mágica e não racional que exerce um papel determinante na prática do consumo. Também tende a se mostrar proveitoso um estudo do comportamento do consumidor de produtos como os da Granado: qual o efeito desses mecanismos de memória sobre as pessoas? Ou seja, o assunto proposto neste artigo rende, ainda, muitas outras análises, seja sobre a mesma empresa, seja sobre outras que também se enquadram na cultura da memória, algumas, inclusive, citadas aqui, como Tok\&Stok e Ellus.

\section{REFERÊNCIAS BIBLIOGRÁFICAS}

HALBWACHS, M. Memória coletiva e individual. In: A memória coletiva. São Paulo: Vértice Editora,1990.

HARVEY, D. Condição pós-moderna: uma pesquisa sobre as origens da mudança. São Paulo: Loyola, 2003.

HUYSSEN, A. Seduzidos pela memória. Rio de Janeiro: Aeroplano Editora /Universidade Cândido Mendes, 2000.

KOPYTOFF, I. “A Biografia cultural das coisas: a mercantilização como processo", in APPADURAI, A. (Org.). A vida social das coisas: as mercadorias sob uma perspectiva cultural. Niteroi: Editora da Universidade Federal Fluminense, 2010.

MORAES, N. "Memória social: solidariedade orgânica e disputas de sentidos", in GONDAR, J. e DODEBEI, V. O que é memória social?. Rio de Janeiro: Contracapa/ Programa de Pós-Graduação em Memória Social da Universidade Federal do Estado do Rio de Janeiro, 2005.

NORA, P. "Entre memória e história: a problemática dos lugares” in Revista Projeto História. São Paulo, 1993. Disponível em http://revistas.pucsp.br/index.php/revph/article/viewFile/12101/876310.

NUNES, M. "Cena cosplay: breves narrativas de consumo e memória pelas capitais do Sudeste brasileiro", in NUNES, M. (Org.). Cena cosplay: comunicação, consumo, memória nas culturas juvenis. Porto Alegre: Sulina, 2015. 
A cultura da memória e suas interfaces com a comunicação e o consumo: um estudo sobre a marca Granado

de Mayara Luma Assmar Correia Maia Lobato

POLLAK, M. "Memória, esquecimento, silêncio" in Estudos Históricos. Rio de Janeiro, 1989. Disponível em http://bibliotecadigital.fgv.br/ojs/index.php/reh/article/viewFile/2278/1417

ROCHA, E.; AUCAR, B. "Sons, histórias e magias: notas sobre misturas e separações na publicidade", in ROCHA, Everardo. PEREIRA, Cláudia e BARROS, Carla (Org.). Cultura e experiência midiática. Rio de Janeiro: Ed. PUC-Rio: Mauad, 2014.

Artigo submetido: 08/05/2016

Artigo aprovado: 02/06/2015 